MATEC Web of Conferences 24,05004 (2015)

DOI: $10.1051 /$ matecconf/ 20152405004

(C) Owned by the authors, published by EDP Sciences, 2015

\title{
Static and dynamic testing of a damaged post tensioned concrete beam
}

\author{
M.P. Limongelli ${ }^{1 a}$, D. Siegert ${ }^{2}$, E. Merliot ${ }^{2}$, R. Vidal ${ }^{3}$, J. Waeytens ${ }^{2}$, F. Bourquin ${ }^{2}$, V. Le Corvec $^{4}$, I. Gueguen ${ }^{5}$, L. M. \\ Cottineau ${ }^{5}$ \\ ${ }^{1}$ Politecnico di Milano, Department of Architecture, Built Environment and Construction Engineering, Milano, Italy \\ ${ }^{2}$ Université Paris-Est, IFSTTAR, Marne La Vallee, France \\ ${ }^{3}$ ADVITAM, VINCI, France \\ ${ }^{4} \mathrm{NECS}$, France \\ ${ }^{5}$ Université LUNAM, IFSTTAR, Nantes, France
}

\begin{abstract}
In this paper are reported the results of an experimental campaign carried out on a post tensioned concrete beam with the aim of investigating the possibility to detect early warning signs of deterioration basing on static and/or dynamic tests. The beam was tested in several configurations aimed to reproduce several different phases of the "life" of the beam: the original undamaged state, increasing loss of tension in the post tensioning cables, a strengthening intervention carried out by means of a second tension cable, formation of further cracks on the strengthened beam. Responses of the beam were measured by an extensive set of instruments consisting of accelerometers, inclinometers, displacement transducers, strain gauges and optical fibres. The paper discusses the tests program and the dynamic characterization of the beam in the different damage scenarios. The modal properties of the beam in the different phases were recovered basing on the responses recorded on the beam during sine-sweep and impact hammer tests. The variation of the first modal frequency was studied to investigate the sensitivity of this parameter to both the cracking of the concrete section and the tension in the cables and also to compare results given by different types of experimental tests
\end{abstract}

\section{INTRODUCTION}

One of the main causes of deterioration of prestressed reinforced concrete beams is the reinforcement corrosion that may cause a complete loss of the bond between concrete and reinforcement beyond the reduction of the steel section. The latter may lead to the breaking of the steel cables with a consequent tension loss allowing the cracking of concrete and the following opening and closing ('breathing') of the cracks during the passage of heavy vehicles. The early stage detection of cracks and/or of tension losses can thus be strategic to improve the structural safety. Access to strand anchorage and retensioning of strands is often difficult or even impossible hence the assessment of the structural performance is often carried out basing on indirect features recovered from vibrational response. Several studies focused on the use of dynamic parameters for damage identification in prestressed reinforced concrete beams have been presented in literature [1]-[7]. All the investigations show that the cracking of the concrete section leads to a global reduction of stiffness and to a local increase of curvature that can be reliably detected basing on the structural response to vibrations (provided the fault induces measurable variations of these features). On the contrary the effect on dynamic parameters of both de-tensioning of the cables 'breathing' cracks are reported to be quite difficult to identify from dynamic parameters [7].

In this paper are presented the results of an experimental campaign carried out on a prestressed reinforced concrete beam. The tests were carried out in the realm of the project SIPRIS (Systèmes Intelligents pour la Prévention des Risques Structurels), aimed to develop intelligent systems for the prevention of structural risk related to the aging of large infrastructures. The specimen was tested in several configurations aimed to reproduce several different phases of the "life" of the beam: the original undamaged state, an increasing loss of tension in the post tensioning cables, cracking induced by loading, after a strengthening intervention, under load inducing further cracks on the strengthened beam. Damage was introduced in a controlled way by means of three points static bending tests carried out loading the beam at several different positions. Before and after each static test, the dynamical response of the beam was measured under sine-sweep and impact tests by an extensive set of instruments deployed on the specimen and consisting of accelerometers, inclinometers, displacement transducers, strain gauges and optical fibres.

This paper discusses the tests program and some preliminary results relevant to the dynamic characterization of the beam in the different phases. The variation of the first modal frequency during the whole test sequence was studied to investigate the sensitivity of

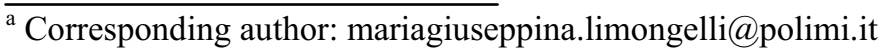

This is an Open Access article distributed under the terms of the Creative Commons Attribution License 4.0, which permits unrestricted use, distribution, and reproduction in any medium, provided the original work is properly cited. 
this parameter to both the cracking of the concrete section and the tension in the cables and also to compare results given by different types of experimental tests and setups.

\section{EXPERIMENTAL TESTS}

\subsection{The tested beam}

A model of a post-tensioned beam was designed to test and validate the capability of several different experimental tests to detect signs of a more or less advanced deterioration of an aging beam. In order to facilitate the handling of the model, control the costs of its construction and limit the load needed to induce the required damage pattern to the specimen, a reduced scaled model was built. It was chosen the smallest size of the model able to correctly reproduce the actual reinforcement and formwork, especially around the anchorages. A total number of 3 tendons were deployed in order to reduce costs and congestion of the reinforced concrete section. Two of them (L1) were straight cables placed at the bottom of the beam; the third one (L2) was a parabolic cable deployed as shown in Figure 2. TGG (toron gainé graissé) cables, each made of one single strand were used and a minimum value of the tension force was imposed in order to allow the opening and closing of the cracks, taking into account that, differently from a real beam, the model was subjected only to the dead load and the concentrated loads applied to induce the opening of the cracks. The tendons were produced with sheath injected with grease and were travelling one by one into the beam; they were not injected.

During the tests the beam, with a gross section of $30 \mathrm{~cm} \times 60 \mathrm{~cm}$, was simply supported at the ends across a clear effective span of $7.9 \mathrm{~m}$ by concrete blocks via two neoprene bearing pads $300 \times 160 \times 30 \mathrm{~mm}$ reinforced with one steel plate $300 \times 160 \times 5 \mathrm{~mm}$.

The properties of the concrete recovered from tests on the material are: 33MPa, Young modulus 29GPa. The ultimate tensile stress of the tendons was $1860 \mathrm{MPa}$, the minimum braking load is $270 \mathrm{kN}$.

\subsection{Experimental setup}

Both three point bending static tests and sine sweep and hammer dynamic tests were carried out on the beam. The loads for the static tests were generated by an hydraulic jack of $100 \mathrm{kN}$ capacity and transferred to the beam via a steel plate (see Figure 3). The hammer tests were performed using a hammer Kiag Swiss 906B with a mass of $9 \mathrm{~kg}$ mass to impact the beam. Sine sweep tests were carried out using a shaker APS 400 Electro-seis shaker.

An extensive set of sensors was deployed on the beam to measure its response: labels and locations of the sensors are reported in Figure 1 and Figure 2.

Accelerations were measured at a sampling rate of $200 \mathrm{~Hz}$ or $400 \mathrm{~Hz}$ with analog accelerometers Silicon design 2210 with a sensitivity of $(800 \mathrm{mV} / \mathrm{g})$ placed vertically at the top of the beam. Displacements were measured by Atek $100 \mathrm{~mm}$ linear potentiometers.

After the formation of the first cracks in phase 2, some crack opening displacement (COD) gauges were deployed at their locations in order to measure their width during the following loading cycles.

Four load cells were used to measure the force in the 3 cables (2L1 and L2) and the point load applied during the static tests.

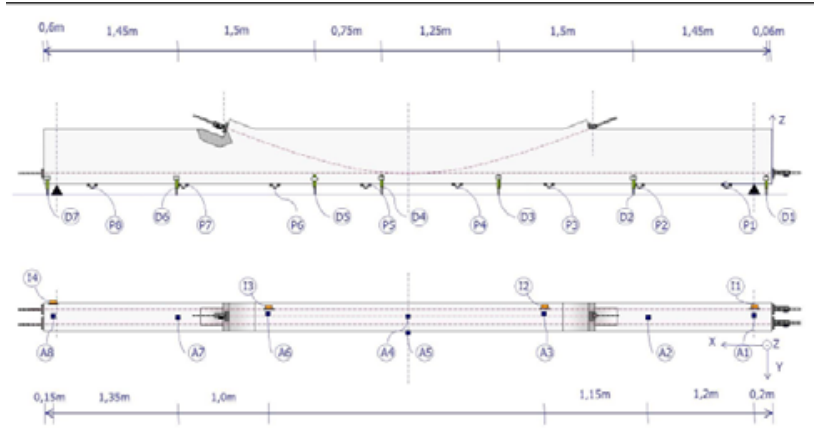

Figure 1: Location of sensors. $\mathrm{D}=$ displacement transducers; $\mathrm{P}=$ strain gauges; $\mathrm{A}=$ accelerometers, $\mathrm{I}=$ inclinometers.

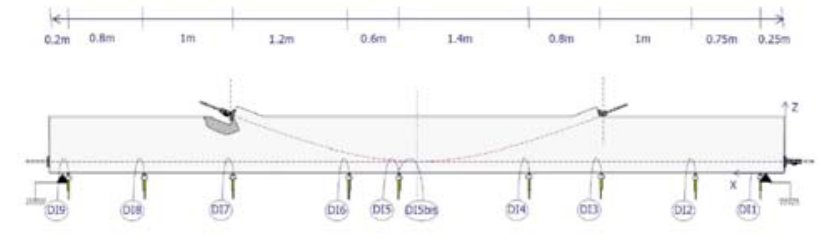

Figure 2: Location of the second network of displacement transducers

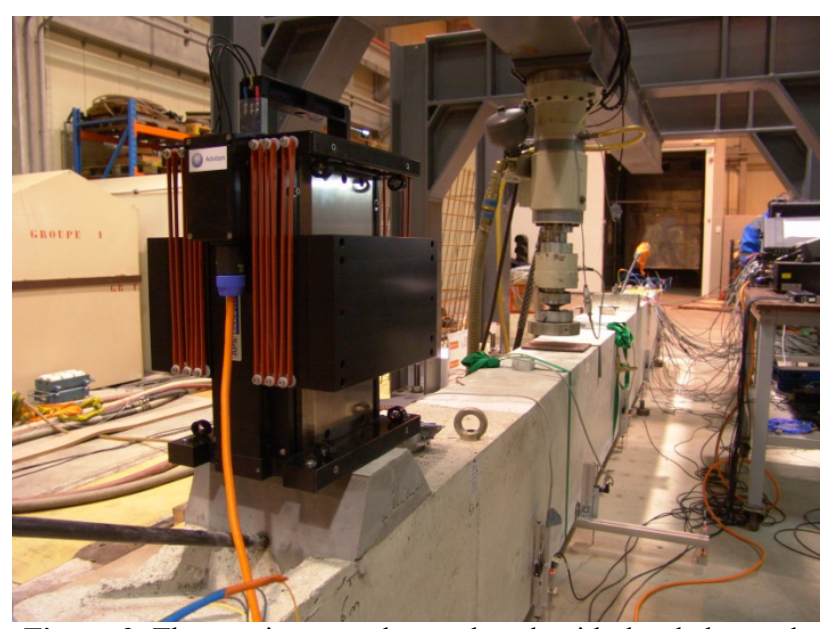

Figure 3: The specimen on the test bench with the shaker and the hydraulic jack.

The acquisition system was a National Instrument 24 bit analogical input modules 9239 system digitizing the eight accelerometers (A1-A8) in 24 bits with two 9239 cards, the temperature with a 9211 card and $\mathrm{K}$ type thermocouples, the eight Omega strain sensors (P1-P8) where digitized by a 9237 card in 24 bits and the three rotations (I1-I3) and seven displacements (D1-D7) in 16 bits with a 9205 card.

\subsection{Test procedure}

In order to investigate the effect of cracks and of the value of prestressing loads on the dynamic characteristics, both static and dynamic tests were performed. The beam was initially tested in its 
undamaged configuration and afterwards a de-tensioning of the bottom cables was carried out. Cracking was subsequently induced by applying a concentrated load at mid-span of the beam and afterward the concentrated load was moved to other locations in order to simulate the effect of a moving vehicle and study its effect on the opening and closing of the crack. A second prestressing cable, aimed to simulate the effect of a repair intervention, was then tensioned and the beam was again cracked and loaded with concentrated load at different sections along its axis in order to compare the behavior of the damaged and the 'repaired' beams.

After each static test, a series of dynamic tests (sine sweeps and hammer tests) were performed to follow the evolution of the dynamic parameters of the specimen.

Specifically the test procedure was organized into 5 phases as follows:

- phase 0: tests on the original undamaged beam;

- phase 1: de-tensioning of the bottom cables (L1 in Figure 1);

- phase 2: cracking at the mid-span and loading in three points bending;

- phase 3: tensioning of the second cable (parabolic cable L2 in Figure 1) and loading of the 'repaired' beam;

- phase 4: cracking at $1 / 3$ of the span length with a point load and loading at different sections to simulate the effect of a moving load.

The tests are detailed in Table 3.

\subsection{Static tests}

Three points static bending tests (denoted in this paper by an $\mathrm{S}$ before the number of the test in the global sequence of tests) were carried out to characterize the specimen and also, in phases 2 and 4 , to induce cracking. The characterization tests were carried out by applying a concentrated load up to $10 \mathrm{kN}$ at different sections and specifically at mid-span, at $1 / 3$ of the clear length $L$ from the left support and at the left support, as specified in Table 3. In order to induce the cracking of the beam, during phase 2 and phase 4 , subsequent cycle of loads with increasing values of the maximum deflection $(3,4$, and $5 \mathrm{~mm}$ ) were imposed.

\subsection{Dynamic tests}

Before and after each static test a number of dynamic tests were carried out to estimate the dynamic characteristics of the beam. Both sine-sweeps (B) and hammer $(\mathrm{M})$ tests were performed and are described in Table 3. The sine-sweeps were performed with the shaker usually placed at about $2 / 3 \mathrm{~L}$ from the left support except for the cases specified in Table 3, which were carried out with different shaker locations, in order to study the effect of the position of the shaker mass on the dynamic characteristics of the beam.

Linear sweep tests on 2 seconds were carried out both in small frequency ranges $(5-10 \mathrm{~Hz} ; 10-20 \mathrm{~Hz} ; 20-40 \mathrm{~Hz} ; 40-$ $80 \mathrm{~Hz}, 80-160 \mathrm{~Hz})$ and in the whole frequency range (5200). Logarithmic sweep tests were carried out over 2 minutes on the frequency range (5-200). Due to the different length of the frequency range considered for the several sine sweep tests, all carried out during 2 minutes, different sweep rates were used. The (constant) sweep rate for a the linear sweep tests over a duration $\mathrm{T}_{\mathrm{d}}$ covering a frequency range from $f_{0}$ to $f_{\mathrm{f}}$, is defined by $\alpha=\left(f_{f}-f_{0}\right) / T_{d}$. It was lower for the tests in smaller frequency ranges: $0.0833 \mathrm{~Hz} / \mathrm{s}$ for the linear tests in the range $10-20 \mathrm{~Hz}$ and $1.625 \mathrm{~Hz} / \mathrm{s}$ for the linear sweep tests in the range $5-200 \mathrm{~Hz}$. For the logarithmic sweep tests the sweep rate was not constant during the test and is given by $\alpha=f_{o} \cdot S \cdot 2^{S t}$ being $S=\left[\log _{2}\left(f_{f}\right)-\log _{2}\left(f_{o}\right)\right] / T_{d}$ over a duration $T_{\mathrm{d}}$. For the tests reported herein, when the frequency of the excitation reaches the first modal frequency (around $13.8 \mathrm{~Hz}$ for the undamaged beam) the sweep rate is: $\alpha=0.61 \mathrm{~Hz} / \mathrm{s}$ that is lower with respect to the sweep rate of the linear sweep in the same frequency range $(5-200 \mathrm{~Hz})$. As will be showed in the following the different values of the sweep rates influences the value estimated for the first modal frequency.

\section{ANALYSIS OF RESULTS}

The discussion of the results will be reported herein for the 5 phases of test in terms of the first modal frequency calculated basing on both sine sweeps and hammer tests data. The shift between the values of frequencies estimated from the different sine-sweep tests depends on the different sweep rate and, consistently with the theoretical findings [12], the value estimated for the first modal frequency increases with the sweep rate. In any case it must be noted that there is a systematic shift between the values of frequency calculated from the different sine sweep tests and from the hammer tests confirming that such differences are mainly due to the type of test employed to estimate the modal frequency.

\subsection{Phase 0. Undamaged beam}

In phase 0 the beam remained undamaged: no cracks were observed after the application of the concentrated loads, consistently with the fact that the calculated values of the internal moments due to the applied loads of $10 \mathrm{kN}$ were lower than the cracking moment of the beam. This is also confirmed by the values of the first modal frequency recovered from the results of the dynamic tests which show only slight oscillations between one test and the following from test 10 to test 32 . Such variations can be ascribed to the variation of the mass distribution due to the change in the position of the shaker $(1 / 4 L, 0,1 / 2 L, 0$, $2 / 3 L$ from the left support) during the different tests (see Table 3). This interpretation has been verified with a very simple model based on Rayleigh coefficient, not reported herein for space limitations.

Static tests in three points bending have been carried out in this phase with a load of $10 \mathrm{kN}$ applied at different locations $(0,1 / 3 L, 1 / 2 L$ from the left support). The same tests were repeated in phase 4 after damaging and repairing the beam. Results are compared in the following. 


\subsection{Phase 1. Detensioning of bottom cables}

In phase 1 the tension $N$ in the cables was gradually reduced by releasing separately each of the two cables from about $120 \mathrm{kN}$ to about $40 \mathrm{kN}$ each. As shown in Figure 9 the first modal frequency stays pretty constant at the decrease of the tension in the bottom cables, whatever the type of dynamic test. It must be noted that during test 34 a lower sweep rate was used with respect to the other linear sweeps hence a respectively lower value of frequency was estimated. The scarce influence of $N$ on the modal frequencies in the cables is consistent with the findings of several experimental tests carried out on prestressed beams [1], [5], [10] and can be explained considering a very simple mechanical model of a supported beam of mass per unit length $m$, length $L$, subjected to a prestress force $N$. The $n$-th natural frequency of vibration is given by [11]:

$$
\omega_{n}^{2}=\frac{1}{m}\left(\frac{n \pi}{L}\right)^{4}\left[\left(E_{b}-\frac{N}{A_{b}}\right) I_{b}+\left(E_{c}+\frac{N}{A_{c}}\right) I_{c}\right]
$$

being $E_{\mathrm{b}}$ and $I_{\mathrm{b}}$ the elastic modulus and the moment of inertia of the beam, $E_{\mathrm{c}}$ and $I_{\mathrm{c}}$ the elastic modulus and the moment of inertia of the cable. Assuming $E_{\mathrm{b}}=26 \mathrm{GPa}$, $I_{b}=0.0054 \mathrm{~m}^{4}$ and $L=7.9 \mathrm{~m}$ the value of the first modal frequency $(n=1)$ is $13.92 \mathrm{~Hz}$ (fitting very well the experimental values reported in Figure 9) for all the values of the tension force $N$.

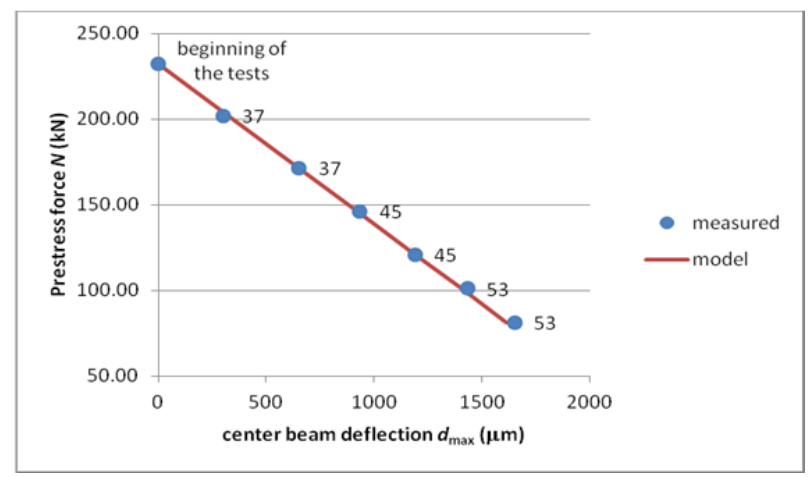

Figure 4: Center-span deflection vs prestress force $\mathrm{N}$

On the contrary, the values of the center-span deflection measured during this phase (T37, T45, T53 in Table 3) decrease linearly with the prestress force $N$, fitting very well the values given by the simple model of a beam on fix end supports under the dead load $q$ and the tension $N$ in the cables.

It must be noted that the deflections during the tests were measured assuming as a reference configuration the one under the dead load $q$ and the initial value of the prestress $\left(N_{\mathrm{o}}=232 \mathrm{kN}\right)$ : the center span deflection $d_{\max }$ reported in Figure 4 is thus the decrease of the deflection due to the reduction of the prestress load, with respect to the reference value at mid span:

$$
d_{\max }=\frac{e L^{2}}{8 E_{b} I_{b}}\left(N-N_{o}\right)
$$

A perfect fit of the results of these static tests is obtained assuming in equation (2) a value of the elastic modulus $E_{\mathrm{b}}$ of the concrete equal to $26 \mathrm{Gpa}$.

\subsection{Phase 2. Cracking at mid span}

In phase 2, following the cracking induced at mid-span during tests S63 and S73, a progressive reduction of the first modal frequency is recorded. In Table 1 the values of the first modal frequency recovered from sine-sweeps in the range $10-20 \mathrm{~Hz}$ are reported together with their variation with respect to the value $f_{0}$ estimated during the last sine-sweep B55 on the undamaged beam.

Table 1. Values of the first modal frequency during phase 2

\begin{tabular}{lll}
\hline Test & $\begin{array}{l}\text { First modal frequency } f_{1} \\
{[\mathrm{~Hz}]}\end{array}$ & $\begin{array}{l}\left(f_{\mathrm{i}}-f_{0}\right) / f_{0} \\
\%\end{array}$ \\
\hline B55 & 13.79 & $\left(f_{0}\right)$ \\
\hline B65 & 12.94 & -6.14 \\
\hline B75 & 12.72 & -7.75 \\
\hline B82 & 12.53 & -9.12 \\
\hline B88 & $12.35^{*}$ & -10.44 \\
\hline B95 & 12.24 & -11.22 \\
\hline B98 & 13.03 & +5.49 \\
\hline
\end{tabular}

The values in the last column give a quantification of the damage suffered by the beam during this phase. It is noted that the reduction of frequency between tests B82 and B88 is partially due to the reduction of the sweep rate which, during test B88 was lower than during the previous test. Immediately after the first cracking of the beam (occurred during test S63) the frequency shows a sharp reduction of about $6 \%$ with respect to the value in the undamaged configuration. After the second damaging test S73 a further (lower) reduction of frequency is recorded. The following static tests (S84-S86), that on the undamaged beam (tests S27, S35, S36), had not induced any cracking or reduction of frequency, cause a further and progressive reduction of frequency (see test B98) due to the progressive increase of the cracks length as measured by the CODs installed on the beam at the cracks location. It must be noted that the increase of frequency recorded during test B98 can explained by the variation in the mass distribution induced by the displacement of the shaker on the left support. This altered the mass distribution on the beam causing, as already seen for phase 0 , an increase of the modal frequency. This is confirmed by the response of the CODs that, during this test, did not record any closing of the cracks that might have induced a stiffening of the beam. The comparison between the variation of frequency between test B93 (after the displacement of the shaker) and following test B103 (after the tensioning of the cable L2) show that the effect of the change in mass distribution can be of the same order of magnitude as the effect of the increase in the cable tension.

\subsection{Phase 3. Tensioning of the upper cable}

In phase 3 the parabolic cable L2 was tensioned inducing a sharp increase of the modal frequency of about $10 \%$ between test $\mathrm{S} 95$ and test $\mathrm{S} 103$ (tests with the same location of the shaker). This was likely to be due to the partial closing of the cracks measured by the CODs placed at mid span. However the frequency did not recover its original value: a loss of about $2 \%$ with respect 
to the original frequency value was found and was probably due to a non complete closing of the cracks. In this phase, after the tensioning of the upper cable L2 three-points static bending tests (S110-S112) were carried out to check the effect of the cracking on the maximum deflection of the beam. Results are discussed in the following section.

\subsection{Phase 4. Cracking of the 'repaired' beam}

In phase 4 the 'repaired' beam was again tested in three points bending (tests S113 and S122) by applying loads of increasing value at the section at $1 / 3 \mathrm{~L}$ from the left support, able to induce cracking at the loading section. As expected, a gradual decrease of the modal frequency was observed during the dynamic tests carried out after cracking (see Figure 9). Further reductions of frequency were measured (tests B135, B140, B141) after the following static tests (S132-S144) even for low values $(10 \mathrm{kN})$ of the applied force. This, together with the measures of the COD, confirming the opening of the cracks during these tests, suggests that a progressive stiffness loss occurred in this phase even for quite low values of the applied forces.

\subsection{Evolution of the 'apparent stiffness' during the 4 phases}

As already shown in section 3.2 for the phase 2, the decrease of the prestress force in the tendons induces an increase of the static deflection of the beam that can be denoted as a decrease of the 'apparent stiffness' of the beam. This occurred also during the other phases of tests as shown by the comparison Figure 5, Figure 6 and Figure 7 showing that:

- the cracking of the beam both at mid span (phase 2) and at $1 / 3 \mathrm{~L}$ from the left support (phase 4) reduces the 'apparent stiffness' of the beam that is there is an increase in deflection under the same load condition;

- after the 'repair' in phase 3 the beam recovers its original apparent stiffness as shown by the comparison between the deflected shapes relevant to phase 0 and phase 3 which are almost superimposed in Figure 5, Figure 6 and Figure 7;

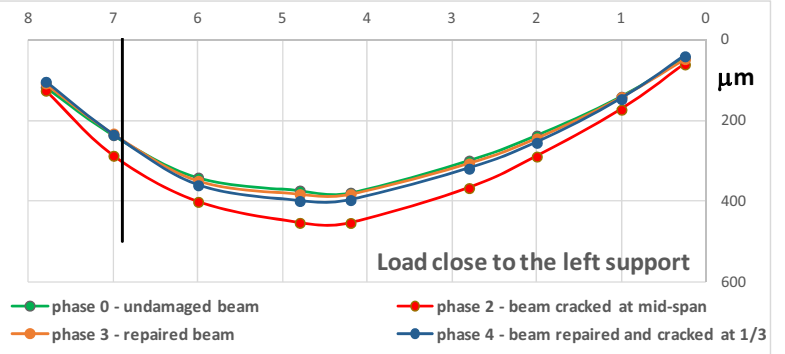

Figure 5: Deflections under three-point bending at the left support

- the cracking at $1 / 3 L$ in the repaired beam induces a non symmetric behaviour of the beam (see Figure 8);

- the cracking at $1 / 3 L$ induces a lower reduction of apparent stiffness on the repaired beam with respect to the cracking at mid-span on the original beam as shown by the comparison between deflections relevant to phase 2 and phase 4 . This is probably due to the higher applied prestressing force in phase 4 due to cable L2.

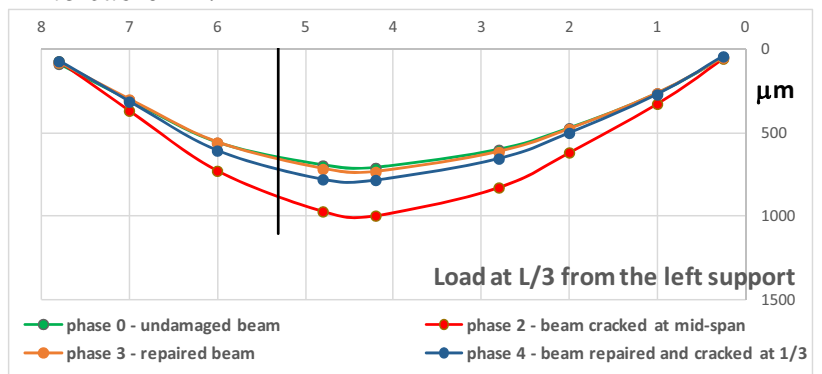

Figure 6: Deflections under three-point bending $L / 3$ from the left support

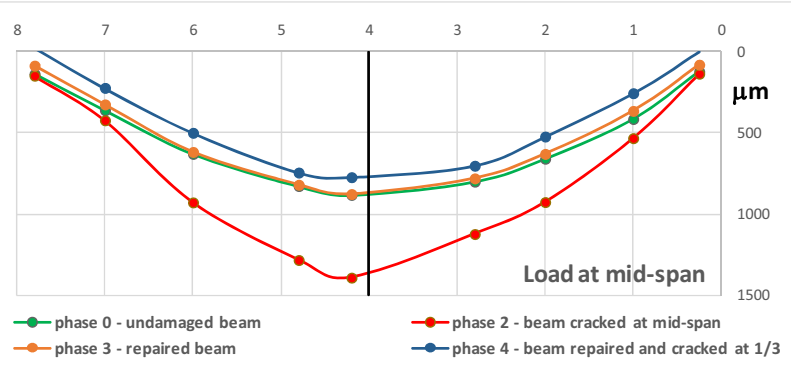

Figure 7: Deflections under three-point bending at mid-span

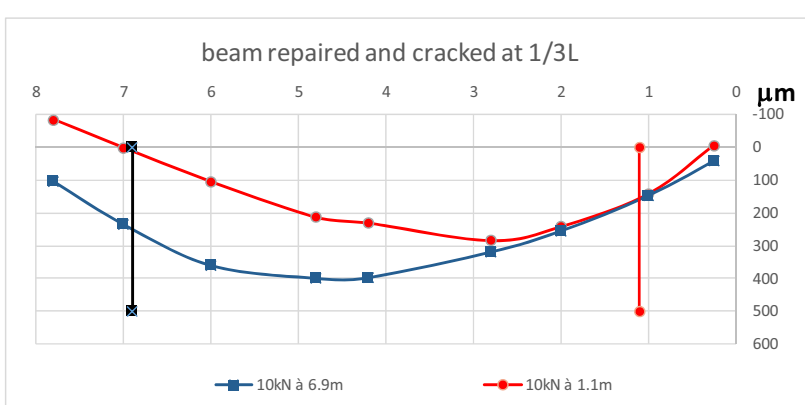

Figure 8: Non symmetric deflection under symmetric loading

\section{FE MODELLING AND MODEL TUNING}

Responses to the sine sweep tests were analyzed using standard technique based Fourier spectral analysis and allowed to detect the first 3 modes of the beam in the undamaged configuration which are reported in the first column of Table 2 . These results were confirmed by the identification of modal parameters developed using the data recovered from the hammer test M43 using Frequency Domain Decomposition (FDD) and the Stochastic Subspace Identification (SSI) methods, implemented in the software package ARTeMIS [9]. The three modes correspond to the first three vertical flexural modes as showed by the identified modal shapes that are not reported here due to space limitation. Due to the locations and to the sensing direction of the acceleration transducers, the lateral flexural modes and the torsional modes were not measured. A preliminary 3D finite element linear model of the beam was built basing on the geometry of the specimen and updated using the experimental values of the first 3 modal frequencies. The 
model was formulated under the following assumptions:

- three nodes elements were used to model the concrete;

- a weight per unit volume of $24 \mathrm{kN} / \mathrm{m}^{3}$ was assumed for the concrete;

- the Poisson ratio of the concrete was assumed equal to 0.275

- initially the boundary conditions were simulated as elastic using vertical and horizontal translational springs whose stiffness was calculated as a function of the mechanical characteristics of the rubber supports of the specimen.

A preliminary modal analysis was carried out assuming a tentative value of the elastic modulus of $29 \mathrm{GPa}$ in order to check the agreement between the modal parameters given by the FE model and the experimental ones. A manual tuning of the parameters of the model (elastic modulus and springs stiffness) was then performed to improve the fitting of the experimental modal frequencies: the best agreement was found assuming fixed supports at the ends of the beam and a value of $E_{\mathrm{b}}=26 \mathrm{GPa}$. This value is in perfect agreement with the results of the interpretation of the static tests reported in section 3.2. In Table 2 is reported the comparison between the modal frequencies recovered from the experimental tests (sine sweeps and impact) on the undamaged beam and the FE model.

Table 2. Modal frequencies of the undamaged beam

\begin{tabular}{llll}
\hline Mode & \multicolumn{3}{c}{$\begin{array}{c}\text { Modal frequency } f \\
{[\mathrm{~Hz}]}\end{array}$} \\
\hline & Sine sweep & $\begin{array}{l}\text { Impact test } \\
\text { B34 }\end{array}$ & FE model \\
\hline 1 & 13.8 & 13.9 & 13.7 \\
\hline 2 & 47.8 & 46.9 & 47.8 \\
\hline 3 & 128.6 & 127.6 & 120.3 \\
\hline
\end{tabular}

In the following of the research a further refinement of the model will be carried out basing of the results relevant to the modal shapes of the specimen identified from the impact tests.

\section{CONCLUDING REMARKS}

In this paper some preliminary results of an experimental campaign carried out on a on a scaled model of a posttensioned reinforced concrete beam have been presented. The effect of different test setup and types of testing, of the cracking and of the de-tensioning of the cables have been analyzed by following the evolution of the first modal frequency of the specimen during the sequence of tests. The analysis shows that:

- the modal frequency is very sensitive to the cracking of concrete hence it can be reliably used as a concrete damage indicator;

- the variations of the modal frequency with the tension in the prestressing cables are hardly detectable unless the latter induces a variation of the cracks state (open vs close);

- the closing of the cracks caused by the increase of tension in the cables does not allow a complete recover of the original value of frequency;

- the tension in the cables is strictly correlated to the 'apparent' stiffness of the beam recoverable from static tests;

- sensible variations of modal frequency can be induced by a variation of the mass distribution hence attention should be paid to the relative mass between the structure and the testing devices;

- the sweep rate adopted for sine-sweep testing may sensibly influence the values of modal frequency;

Further analyses are in progress to investigate the evolution of the higher modes frequency during the sequence of tests and to refine the FE model using experimental modal shapes.

\section{REFERENCES}

[1] Kato, M. and Shimada, S. (1986) "Vibration of PC Bridge During Failure Process." Journal of Structural Engineering ASCE 112(7) p. 1692-1703.

[2] Saiidi, M., Douglas, B., and Feng, S. (1994). "Prestress Force Effect on Vibration Frequency of Concrete Bridges." J. Struct. Eng., 120(7), 22332241.

[3] Brincker R., Andersen P., Kirkegaard P.H., Ulfkjær J.P. (1995) "Damage Detection in Laboratory Concrete Beams" Proc. of the 13th International Modal Analysis Conference, Nashville, USA, pp. 668674, 1995.

[4] Razak H A and Choi F C (2001). "The effect of corrosion on the natural frequency and modal damping of reinforced concrete beams". Engineering Structures 23 1126-1133.

[5] Jacobs, S., De Roeck, G. (2003). Dynamic testing of a pre-stressed concrete beam. 6th National Congress on Theoretical and Applied Mechanics. 6th National Congress on Theoretical and Applied Mechanics, May, 2003.

[6] Zhou Z, Wegner L. D., Sparling B. F., (2010) "Structural health monitoring of precast concrete box girders using selected vibration-based damage detection methods," Advances in Civil Engineering, vol. 2010, Article ID 280685, 21 pages.

[7] Kim J.T., Yun C.B., Ryu YS, Choi H.M. (2003). "Identification of prestress-loss in PSC beams using modal information. Struct Eng Mech, 17 (3-4) (2003), pp. 467-482.

[8] M.A. Abraham, S.Y. Park, N. Stubbs, Loss of prestress prediction on nondestructive damage location algorithms, SPIE, Smart Structures and Materials. 2446 (1995) 60-67.

[9] http://www.svibs.com

[10] Capozzucca R. (2011). Damage assessment in PRC and RC beams by dynamic tests. J. Phys.: Conf. Ser. 305(1) 012098 doi:10.1088/1742-6596/305/1/012098.

[11] Dall'Asta A., Dezi L. (1996). "Discussion on Prestress Force Effect on Vibration Frequency of Concrete Bridges." J. Struct. Eng. 458-459.

[12] Ewins D.L. (2000). Modal testing: Theory, Practice and Application - Second Edition. Research Studies Press Ltd. 


\section{EVACES'15}

Table 3. Static and Dynamic tests performed on the beam

\begin{tabular}{|c|c|}
\hline \multicolumn{2}{|c|}{ phase 0: Undamaged beam } \\
\hline B10-B14 & Linear sine sweep. Shaker at $1 / 4 \mathrm{~L}$ from the left support \\
\hline M 15 & Hammer test \\
\hline B $16-\mathrm{B} 21$ & Linear sine sweep. Shaker at the left support (16-21) and at the mid span (22-26) \\
\hline $\mathrm{S} 27$ & Static test. Load at mid span up to $10 \mathrm{kN}$ \\
\hline B 28-B34 & Linear sine sweep. Shaker at 3/4L from the left support \\
\hline S35-S36 & Static test. Point load up to $10 \mathrm{kN}$ at $1 / 3 \mathrm{~L}$ from the left support and at the left support \\
\hline \multicolumn{2}{|c|}{ phase 1: Detensioning of the bottom cables } \\
\hline T37 & Detensioning of the bottom cables from about $120 \mathrm{kN}$ to about $40 \mathrm{kN}$ each \\
\hline B38-B42 & Linear sine sweep tests \\
\hline M43-M44 & Hammer tests. \\
\hline T45 & Detensioning up to $61 \mathrm{kN}$ \\
\hline B46-B51 & Linear sine sweep tests \\
\hline M52 & Hammer test. \\
\hline T53 & Detensioning up to $40 \mathrm{kN}$ \\
\hline B54-B59 & Linear sine sweep tests \\
\hline M 60 & Hammer test. \\
\hline BG 61 & Logarithmic sine sweep $(5-200 \mathrm{~Hz})$ \\
\hline BL 62 & Linear sine sweep $(5-200 \mathrm{~Hz})$ \\
\hline \multicolumn{2}{|c|}{ phase 2: Cracking at the mid-span } \\
\hline S63 & Static test. Load at mid span up to $3 \mathrm{~mm}$ max deflection \\
\hline B64-B71 & Linear sine sweep (64-69), linear and logarithmic sine sweep 5-200Hz (70-71) \\
\hline M72 & Hammer test. \\
\hline S73 & Static test. Load at mid span in 3 steps up to $5 \mathrm{~mm}$ max deflection \\
\hline B74-B82 & Linear sine sweep $(74-79,82)$, linear and logarithmic sine sweep $5-200 \mathrm{~Hz}(80-81)$ \\
\hline M83 & Hammer test. \\
\hline S84-S86 & Static test. Point load $10 \mathrm{kN}$ at mid span, at $1 / 3 \mathrm{~L}$ from the left support, at the left support. \\
\hline B87-B97 & Linear sine sweep (87-92, 95-97), linear and logarithmic sine sweep 5-200Hz (93-94) \\
\hline B98-B100 & Linear sine sweep. Shaker on the left support. \\
\hline \multicolumn{2}{|c|}{ phase 3: Tensioning of the upper cable } \\
\hline $\mathrm{T} 101$ & Tensioning of the upper cable in 2 steps $48 \mathrm{kN}$ and $120 \mathrm{kN}$ \\
\hline B102-B109 & Linear sine sweep (102-107), linear and logarithmic sine sweep 5-200Hz (108-109) \\
\hline $\mathrm{S} 110-\mathrm{S} 112$ & Static test. Load $10 \mathrm{kN}$ at the left support, at mid span, at $1 / 3 \mathrm{~L}$ from the left support \\
\hline \multicolumn{2}{|c|}{ phase 4: Cracking of the repaired beam } \\
\hline $\mathrm{S} 113$ & Static test. Load at $1 / 3$ from the left support up to $1.3 \mathrm{~mm}$ max deflection \\
\hline B114-B121 & Linear sine sweep (114-119), linear and logarithmic sine sweep 5-200Hz (120-121) \\
\hline $\mathrm{S} 122$ & Static test. Load at $1 / 3$ from the left support up to $3.5 \mathrm{~mm}$ \\
\hline B123-B130 & Linear sine sweep (123-128), linear and logarithmic sine sweep 5-200Hz (129-130) \\
\hline M131 & Hammer test. \\
\hline S132-S133 & Static test. Load $10 \mathrm{kN}$ at $1 / 3$ from the left support (132), at mid span (133). \\
\hline B134-B141 & Linear sine sweep (134-139), linear and logarithmic sine sweep 5-200Hz (140-141) \\
\hline S142-S144 & Static test. Load $10 \mathrm{kN}$ at $1 / 3$ from the right support, at the left support, at the right support. \\
\hline
\end{tabular}


MATEC Web of Conferences

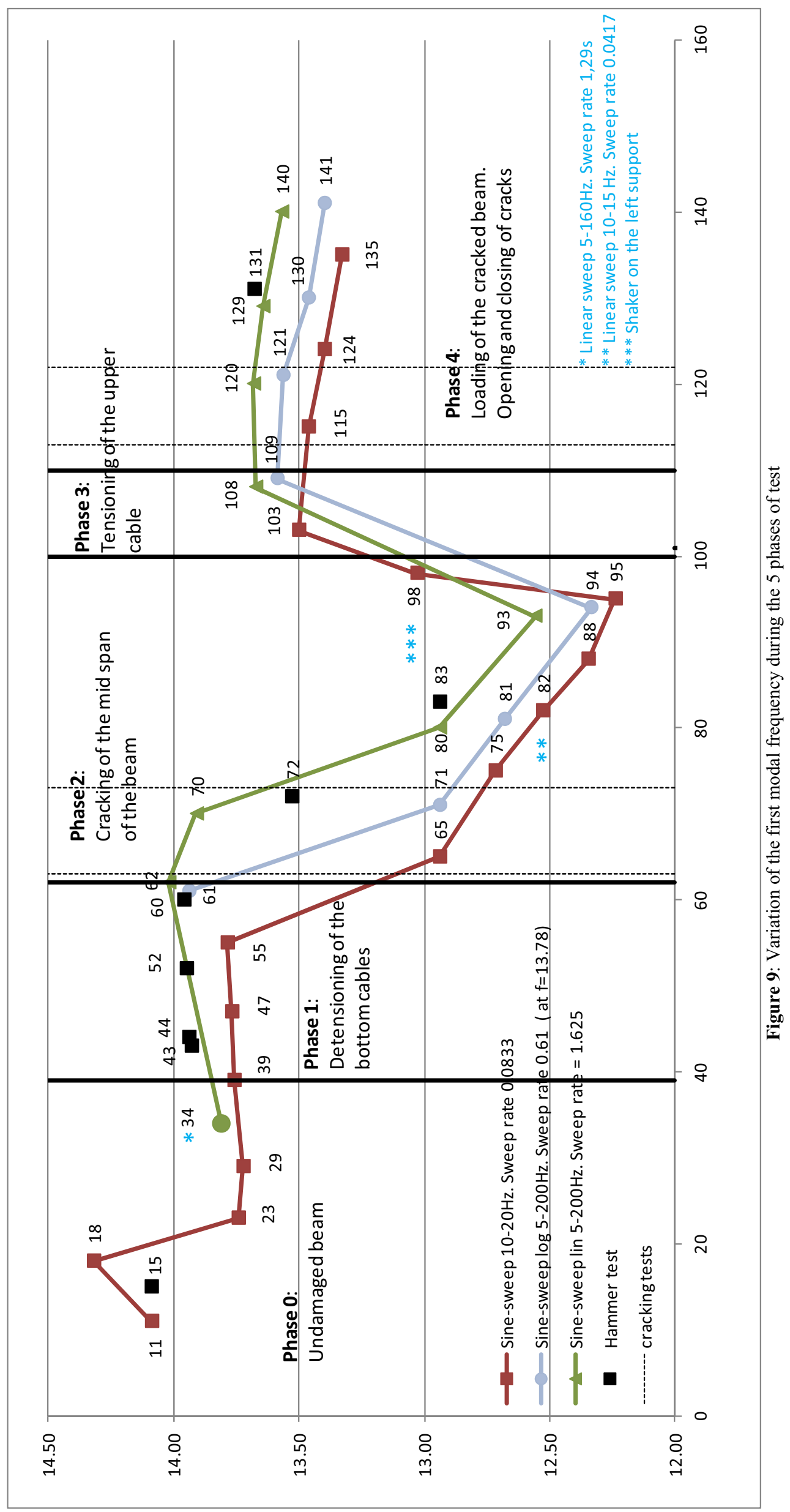

